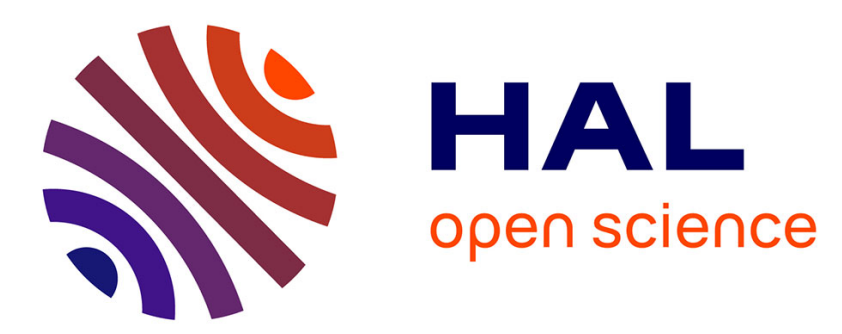

\title{
Using a multi-criteria decision aid methodology to implement sustainable development principles within an Organization
}

Myriam Merad, Nicolas Dechy, Lisa Serir, Michel Grabisch, Frédéric Marcel

\section{To cite this version:}

Myriam Merad, Nicolas Dechy, Lisa Serir, Michel Grabisch, Frédéric Marcel. Using a multi-criteria decision aid methodology to implement sustainable development principles within an Organization. European Journal of Operational Research, 2013, pp.603-613. 10.1016/j.ejor.2012.08.019 . halshs00752736

\section{HAL Id: halshs-00752736 \\ https://shs.hal.science/halshs-00752736}

Submitted on 16 Nov 2012

HAL is a multi-disciplinary open access archive for the deposit and dissemination of scientific research documents, whether they are published or not. The documents may come from teaching and research institutions in France or abroad, or from public or private research centers.
L'archive ouverte pluridisciplinaire HAL, est destinée au dépôt et à la diffusion de documents scientifiques de niveau recherche, publiés ou non, émanant des établissements d'enseignement et de recherche français ou étrangers, des laboratoires publics ou privés. 


\section{Accepted Manuscript}

Innovative Applications of O.R

Using a multi-criteria decision aid methodology to implement sustainable development principles within an Organization

Myriam Merad, Nicolas Dechy, Lisa Serir, Michel Grabisch, Frédéric Marcel

PII: S0377-2217(12)00642-X

DOI: http://dx.doi.org/10.1016/j.ejor.2012.08.019

Reference: EOR 11251

To appear in: European Journal of Operational Research

Received Date:

15 June 2010

Accepted Date:

27 August 2012

Please cite this article as: Merad, M., Dechy, N., Serir, L., Grabisch, M., Marcel, F., Using a multi-criteria decision aid methodology to implement sustainable development principles within an Organization, European Journal of Operational Research (2012), doi: http://dx.doi.org/10.1016/j.ejor.2012.08.019

This is a PDF file of an unedited manuscript that has been accepted for publication. As a service to our customers we are providing this early version of the manuscript. The manuscript will undergo copyediting, typesetting, and review of the resulting proof before it is published in its final form. Please note that during the production process errors may be discovered which could affect the content, and all legal disclaimers that apply to the journal pertain. 


\title{
Using a multi-criteria decision aid methodology to implement sustainable development principles within an Organization
}

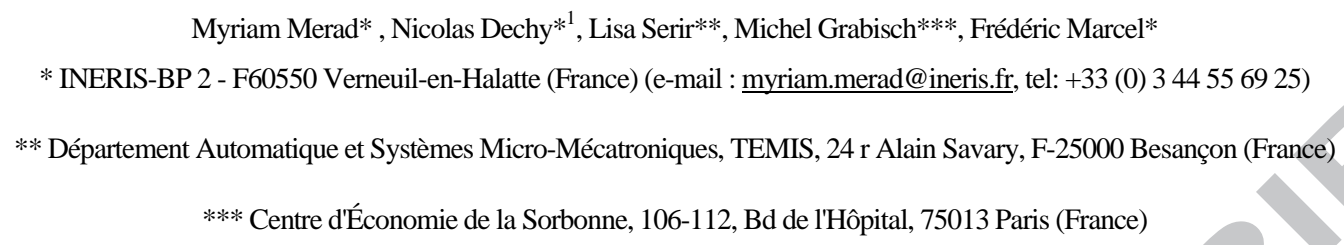

\begin{abstract}
:
The implementation of Sustainable Development (SD) within an Organization is a difficult task. This is due to the fact that it is difficult to deal with conflicting and incommensurable aspects such as environmental, economic and social dimensions. In this paper we have used a Multi-Criteria Decision Aid (MCDA) methodology to cope with these difficulties. MCDA methodology offers the opportunity to avoid monetary valuation of the different dimensions of the SD. These dimensions are not substitutable for one another and all have a role to play. There is an abundance of possible aggregation procedures in MCDA methodology. In this paper we have proposed an innovative method to choose a suitable aggregation procedure for SD problems. Real life case studies of the implementation of an outranking approach (i.e., ELECTRE) and of a mono-criterion synthesis approach (i.e., MAUT approaches based on the Choquet integral) were done to respectively rank 22 SD strategic actions within an expertise Institute and rank 20 practical operational actions to control energy consumption of the Institute's buildings.
\end{abstract}

\section{Keywords:}

Sustainable Development indicators, Sustainable Development action plan, Multi-Criteria Decision Aid, ELECTRE and Choquet Integral.

\section{Introduction}

Sustainable Development (SD) within an Organization can be achieved by Corporate Social Responsibility (CSR). In France, CSR is denoted by Responsabilité Sociétale des Organisations (RSO) - Organization Societal Responsibility (OSR) and aims to find an equilibrium between economic, social and environmental considerations. With all these considerations, the management of the Organization is becoming more and more complex due to the increasing number of: (i) regulations to fulfill, (ii) other actors that are impacted by the decisions of the Organization who must be consulted and (iii) indicators (parameters or criteria) to follow.

${ }^{1} \mathrm{~N}$. Dechy was at INERIS during the study and is now working at IRSN. 
As it has been commonly stated in classical economic and management theories, firms need to make profits in order to survive. However, management needs to adopt a viable posture in the face of a variable environment. This new vision promoted by the SD principle has changed the way profit, costs and risks are considered. Indeed, profit is not only financial quantification (e.g. euro), but also represents social and environmental gains (e.g. more diversity within the organization and less pollution). The SD principle needs a strong political engagement because of the constant need to seek equilibrium between economic, environmental and social concerns (see Figure 1) that cannot be obtained without the implementation of a participative governance model.

Figure 1. Sustainable Development principle

To move from an ethical perspective of operation to an action, the SD principle requires methods and tools to be implemented. Multi-criteria decision aid methodology can help practitioners to deal with the expectations and perceptions of different actors with varied objectives to fulfill (economic, social and environmental). Our paper will focus on the contribution of multi-criteria decision aid methodology in outlining SD problems within the Organization and structuring recommendations for different actors inside and/or outside the Organization. We will also discuss various tools (aggregation procedures) that can be achieved in various contexts. We will cover these topics by discussing the use of multi-criteria decision aid methodology for the implementation of SD principles in a Public Organization whose mission is to prevent industrial and environmental hazards.

\section{Multi-criteria decision aid methodology for the implementation of the SD principle within the Organization}

To reach a sustainable development following the SD principle, the Organization should constantly seek for equilibrium (to reduce risks and increase benefits) with respect to interactions within its external environment (Figure 2 (a)).

(a)

(b)

Figure 2. The Organization and its environment (a) and 3 levels of decision in the Organization (b)

\subsection{SD and the different level of decision with the Organization}

Different actions can be taken at different levels of decision-making within the Organization. These levels (Figure 2 (b)) are differentiated according to: (i) the practical objectives that are sought, (ii) the nature and the level of information/knowledge that is available and (iii) the potential impacts: 
The strategical level. At this level, the objective of decision-making is action planning. The decision is a long term decision (more than 8 years) and is dominated by both political and regulatory dimensions. At this level, the information is abundant but imprecise and difficult to sort and select.

The tactical level. The decisions/actions are less influenced by political and regulatory dimensions than at the strategical level. The decision is a middle term one (4 years). At this level, the decisions are under the constraints and objectives within the Organization (social, technical and economic). This level is represented by the intermediate staff of management.

The operational level. Decision-making pertains to short-term goals achieved in less than 1 year. The decisions made are more concrete involving technical information which is often specialized, precise, and more specific than the higher levels.

For each level of decision, the SD principle makes the decision maker reach for an equilibrium between economic, social and environmental concerns (risks/costs, benefits). The difficulty here is to both (i) clarify what measures (actions) must be taken at each level of decision-making and (ii) consolidate all the measures at each level in order to become a Societal Responsible Organization (SRO). In order to go beyond these limits, we have chosen to use a multi-criteria decision aid methodology. The methodology is based on a two-step approach. The first step consists in "outlining and structuring the problem". To do so, it is necessary to identify and explicit the stakes, the constraints, the actors and stakeholders concerned or affected by the SD problematic and then to choose the adequate method according to the level and to the nature of information and knowledge. The second step is the "implementation of a method". This step consists in restructuring the available information according to the method to be used and analyzing the results of the method in order to provide the adequate recommendation to the decision-maker. The figure 3 describes these two steps.

Figure 3. Multi-criteria decision aid methodology: the link between the Analyst and the Decision Maker

The problematic of "Description and structuring" (Figure 3, point 2) in decision sciences is a challenging problem. We have chosen to use an Organizational Analysis (OA) technique crossed with a "contextual diagnostic" to describe the SD problem (Merad, 2010). These two techniques are imported from social sciences and help to make explicit what is at stake and what are the rationale between actors inside and/or or outside the Organization.

Once the context is described, the Analyst should move to a prescriptive model (Figure 3, point 3). MCDA is an interesting methodology that can help the Decision Maker (DM) in respecting the accountability principle that is a challenging aspect when dealing with sustainable development. 


\subsection{Multi-criteria decision aid methods: general principles}

The great majority of decision aid methods tend to structure the decisional aid process into three principal phases: formulation of decision-aid problematic, exploitation, and recommendations (Figure 4). Formulating a decision-making problem consists in finding an adequate model for the decision-making process. In a context where reality is represented by a multi-criteria form, this first phase consists of:

Describing the decision making context and process. This requires the identification of the actors, their value systems and the different significant points that affect the decision making process which can vary in time.

Defining the actions that are elements of decision-making. Identifying decision making situations which consists of looking at how the recommendation or the results should be presented (e.g., is the aim behind SD methodological or procedural with an intention to be repeated?); and identifying the spirit in which the decision aid process was designed.

Defining a set of criteria and a set of indicators and modeling the consequences of actions and drawing up criteria in order to compare the different actions with each other.

Figure 4. Multi-criteria decision aid method applied to the implementation of the SD principle

This first phase is undoubtedly the most delicate one because the conclusions reached and the recommendations provided depend on the way in which the SD principle is considered. The second phase is more mathematical. The so-called operational phase consists of defining or choosing an "aggregation procedure" for the available information for each action with the aim of reaching an overall conclusion (recommendation) that will serve to lend support to the decision.

\subsection{From a Partial Evaluation to an Global Evaluation: Aggregation}

Aggregating the evaluations of an action $\mathrm{x}$ taking into account the evaluations of the different criterion $g_{j}$ and opinions on the importance that each player gives the F criteria is also a way of asking the question of compensation levels that one wishes to obtain between the criteria (Vincke, 1986). For every multi-criteria decision aid method there is a choice made of the kind of logic applied:

Compensatory. The most well known example is the case of a weighted sum. Consequently the aggregation methods found in this category range derive from the postulate that it is possible to compare, in an absolute manner, the various evaluations of an action $\mathrm{x}$. 
Consequently a high evaluation of one criterion $g_{j 1}$ ( $g$ is the criteria function) will compensate for a lower evaluation of another criterion $g_{j 2}$.

Partially-compensatory. A certain level of compensation is acceptable.

Non-compensatory. Applying these kinds of methods, the evaluations of an action $\mathrm{x}$ based on criteria $g_{j}$ are not mutually compensatory.

Furthermore, there are several aggregation procedures that can be gathered into three categories, each relating to an operational approach to performance aggregation (Roy and Bouyssou, 1992):

Using a single summary criterion. This comprises summarizing the criteria family into a single criterion. In this approach incomparability is ruled out (see Roy and Bouyssou, 1992).

By upgrading the summary. This comprises moving from a comparison relationship drawn up for each criterion to a global comparison relationship. This approach accepts incomparability.

By reaching an interactive local judgment with trial and error iterations. If in the other two approaches the rules are set out to provide an exhaustive summary response, this is not the case here. This is because aggregating is the result of a sequence of local judgments.

\section{Which aggregation procedures should be chosen for the implementation of the SD principle?}

When facing the decisional problem that consists in the implementation of the SD principle, actors are brought to discriminate and/or choose between various options/actions/projects whose consequences are often badly controlled insofar as they are confronted with complex problems with multiple dimensions and whose stakes are often of big importance.

Looking at the literature about the use of Multi-Criteria Aggregating Procedure (MCAP) in the implementation of SD principles, we came to the following remarks:

- There is not a lot of research and work that has been done on the implementation of the use of MCAP to the implementation of the SD principle (Faucheux et al., 1998).

- MCAP is mainly applied as regards environmental management problems (Janssen, 1992 ; Munda, 1995 ; Paruccini, 1994) mainly in Canada (Chevallier, 1999) and in Switzerland (Maystre et al., 1994 ; Maystre and Bollinger, 1999).

- Methods such as ELECTRE (Hokkanen and Salminen, 1997 ; Kangas et al., 2001 ; Hokkanen et al., 1998), PROMETHEE (Behzadian and all, 2010 ; Hokkanen and Salminen, 1997) and AHP (Rezaei-Moghaddam and Karami, 2008 ; Ramanathani and Ganesh, 1995 ; 
Girard and De Toro, 2007) are largely applied to environmental management problems. The paper by Kowalski (2009) provides an interesting synthesis of the methods applied to the energy management problems.

- We found only one document giving applications at the level of an Organization (company) (Omann, 2004). The case study presented is about how to obtain a sustainable Product Service Systems and the method used is based on MACBETH.

- Let us notice that the majority of studies published are generally at a national scale. The application of the SD principle within an Organization (ex. company, plant, ...) is largely different from a territory (ex. national, regional, ...) mainly because of the number of DMs: one main in the case of the Organization (ex. the General director), and several when dealing with territories (ex. Mayors, all the general directors of the Organizations within the territory, local administrative authorities, ....). It is also different because a territory is an open system (where coexist different levels of responsibility in terms of decisions and where the borders of what is in and what is out is not delimited legally speaking) and the Organization a more closed one (Merad, 2010).

According to these observations, we have considered as central to try to elaborate some recommendations on the use of MCAP for the implementation of SD principle within an Organization. We have previously stressed the necessity to consider the fact that different levels of concern (levels of decision) coexist in the same Organization. We argue that for each level of concern, there is a set of characteristics that do constrain the decision aid process. These constraints can help us to make a choice between the different multi-criteria aggregating procedures (MCAP) used, also considering that each MCAP must respect specific assumptions and postulates. In a more generic way, Guitouni and Martel (1998) have proposed seven key questions to choose an MCAP. These general questions are useful for global decision-making contexts. In a more specific context, De Monti and al. (2003, 2004) and Omann (2004) have proposed respectively a set of quality criteria and a set of questions to respectively evaluate or choose MCDA methods when implementing the SD principle.

In our case, we wanted to propose a method to choose a MCAP when implementing the SD principle within an Organization. Based on the different papers listed above and the work done by Merad (2004, 2010), we have proposed that the implementation of the SD principle within an Organization can lead to two major categories of problems:

Category A "A need to debate and initiate a dialogue between actors about the way to make SD principle move from philosophical concept to pragmatic and operational tool'. The 
objective is to build a common representation of the boundary of the application of the SD principle and to rationalize the involvement and the investment in SD actions that will be done and will have an impact on both the tactical and the operational level within the Organization. In this category of problem the information is more qualitative and the actors involved are those that belong to the strategic and the tactical levels of decision (Figure 2). As example: the implementation of the ISO 26000 norm about Corporal Social Responsibility.

Category B "A need to rationalize the implementation of SD actions". In this category, the information is more quantitative and the actors involved are those of the operational level of decision (Figure 2). As example: the implementation of a Displacement Action Plan to reduce $\mathrm{CO}_{2}$ emission.

This prophylaxis based on two categories leads us to suggest some conditions on the use of MCAP for the implementation of the SD principle within an Organization:

Category A. We suggest using MCAPs based on:

- $\quad$ MCAPs that are non- or only partially-compensatory such as summary upgrades.

- Preference structures (see Roy and Bouyssou, 1992) of types (S, R) seem of interest to us because the incomparability relation $\mathrm{R}$ invites the actors to question themselves on their representation of the problem, on the relevance of the set of criteria used, etc.

- Using information that is both quantitative and qualitative.

- The ability to let the different opinions of the actors and actors involved be explicitly expressed.

Category B. We suggest using MCAPs based on:

- Single summary criterion type PMCAs.

- Preference structures (see Roy and Bouyssou, 1992) of types (I, P) or even (I, P, Q) seem of interest to us. Given the strong tendency of operational actors to ask for precise data and concise conclusions, the incomparability relationship $\mathrm{R}$ is not seen as an invitation to debate, but a problem blamed on the method.

Hereafter, we will give an illustration on the use of the multi-criteria decision aid methodology focusing on the prescriptive phase (Figure 3) of the decision aid process. The illustration is the implementation of a Sustainable Development Plan (SDP) in a public institute of expertise. The results of the implementation of the descriptive phase are presented on the papers by Merad (2010). Two MCAPs were chosen based of these two categories: 
ELECTRE III (see Roy and Bouyssou, 1992) to rank a set of SD actions. This MCAP offers the possibility of dealing with both qualitative and quantitative information and deals with the preference of a large variety of stakeholders with different backgrounds and constraints. The Problem of ranking a set of SD actions is a decision problem done at a strategical level of the Organization. With ELECTRE III, we have the opportunity to use the preference structures of types (S, R). The S, R relations will help us in creating a deliberation context between stakeholders and discuss about the impact of the SD action plan (see category A).

Choquet integral (Labreuche and Grabisch, 2006) to rank actions to control energy consumption of the Institute's buildings. The problem is an operational and practical problem. The stakeholders involved are specialists in this field that are able to give precise information and that expect an (I, P) preference structure (see category B).

\section{Example of the implementation of the SD principle in a Public Institute in the field of industrial environment and risks}

INERIS is a public institute in the field of industrial environment and risks, and works as a technical support for the French ministry of environment. As a public institute, INERIS must be exemplary when it comes to the implementation of the SD principle. In 2008, INERIS signed, with other public organizations, the Sustainable Development Charter. This one reinforces the engagement of the Institute in favor of the SD principle. In a letter addressed to INERIS on April 6, 2009, the French Ministry of Environment invited the Institute to frame a Sustainable Development Plan (SDP). In this SDP, the Ministry asked to: identify some strategic objectives, list a set of actions respecting 3 priorities (responsible sourcing, eco-responsibility, social responsibility) and identify a set of indicators to follow the execution of the actions at an operational level.

Even if the SD principle has been known and defined since 1987 in the Brundtland report, it is quite innovative in the French public Organization to make explicit and rationalize a set of actions that will be followed each year, and contribute to SD, considering economic, social and environmental aspects. How can all the possible actions at INERIS be identified? How can we rank the actions from the most beneficial actions to the less beneficial ones?

In what follows, we have chosen to discuss the use of two methods to rationalize the SD principle.

\subsection{Use of ELECTRE III MCAP for the ranking of SD actions for all the Institute}

Actions to implement SD principles within the INERIS Organization are those which contribute to achieve an accepted equilibrium between environmental, social and economic constraints. An 
organizational analysis was carried out within the Institute. This analysis, mainly based on investigations aiming at explicating the nature of the relations between actors and the inherent stakes that influence the sustainability of the Institute, has helped us to identify more than 48 actions proposed by the staff (Merad, 2010). These actions were reduced to 22 actions that respect the constraints made by the ministry of Environment. These actions are presented in the table 1 below:

Table 1. List of 22 SD actions for INERIS

These actions are under the responsibility of the top management staff within the Institute. Each of them has a different role and perspective but share common tasks that consist of seeking a financial equilibrium of their Division and defining a strategical vision (see Category A, chapter 2).

\subsubsection{Set of criteria and weighting}

These actions are coordinated by the General Director and his Advisory board (Staff of directors). Criteria were needed to be able to organize a discussion between the Board of Directors and compare one action to the other according to the different available points of view. Two sets of criteria were asked to be necessary: expected benefits due to the implementations of the SD actions and necessary expenses due to the implementations of the SD actions. The 22 SD actions are assessed according to the three criteria of benefits and three criteria of cost (expenses).

a) Set of benefit criteria (see figure 5): The 22 actions have all positive impacts in terms of environmental, social and economic responsibility that can be estimated qualitatively. After a debate with the Board of Directors, we have considered that it was possible to identify 4 levels for each criterion. Each action takes a value going from 1 (the impact is difficult to estimate or does not have impact) to 4 (high level of impact):

Figure 5. Set of benefit criteria

b) Set of expense (cost) criteria: The implementation of the 22 actions will represent an expense for the Institute. As presented below, three criteria will be used to estimate the surplus of expenses involved for the implementation of the SD actions: internal expenses (work done by the Institute staff), external expenses (e.g., scientific and technical subcontracting) and investments (e.g., equipment). Each action takes a value going from 0 (not possible to assess), 1 (low level) to 4 (high level) for the two criteria "Internal expenses" and "Investments" and a value of 0 (not possible to assess), 1 (low level) to 3 (high level) for the criterion "External expenses". To each level of the "External expenses" and the "Investments" criteria corresponds an interval in K€ (see figure 6). To each level of the "Internal expenses" criterion corresponds an interval estimated in man/year (see figure 6). 
Figure 6. Set of cost criteria

The choice of criteria-specific weightings has required the formalization of the opinion given by the staff of Directors. We have chosen to use the 'cards method' (Merad, 2002 and Figuera and Roy, 2002) because this method is well-adapted to ELECTRE III and can help to frame a common representation of the SD strategic problem between the staff of directors. Each criterion is associated to a card and presented to the Directors that are asked to sort the cards from the least important to the most important criterion and to insert blank cards to indicate the relative importance among criteria from one rank to the next. This revised Simos method (Roy and Figuera, 1998) has many advantages, namely preventing criteria from being eliminated by a zero-weight assignment and incorporating the various weightings ascribed by Directors as a function of their expectations and preferences (Merad, 2002). This method was applied separately to obtain one weighting set to the benefit criteria and another weighting to the cost criteria (see Table 2). Each of the three benefit criteria has an equivalent weight in the choice of the priority between SD actions. The weight of the internal expenses ( $\left(\mathrm{D}_{\text {Int }}\right)$ was considered to be equivalent to the weight of the investment (Inv). The weight of both the Inv and $D_{\text {Int }}$ are strictly higher than the external expenses $\left(D_{\text {Ext }}\right)$.

\subsubsection{From a partial to a global assessment of the SD actions}

At this level of decision (strategical and tactical) see Figure 2 (b), most of the available information is qualitative. This is mostly due to the fact that there is a need to frame a common representation of strategical objective of the Institute once the actions are identified and the criteria specified. This problem belongs to the "category A" defined in chapter 2. The "category A" proposes a set of MCAP based on preference structures of types (S, R). The ELECTRE MCAPs (see Roy and Bouyssou, 1992) correspond to this category. The Institute is very familiar with ELECTRE methods and so we have decided to use ELECTRE III (see Merad, 2004).

By conducting a set of interviews within the staff of Directors, it was possible to fill out the SD actions dashboard. Each action is coordinated by a Director. Each Director gives an estimation of the SD action according to the two sets of criteria. These assessments are carried out once per year and synthesized in "Impacts SD dashboard" and consolidated in a collegiate way.

Table 2. Impacts SD Dashboard

Each action is compared to the others according to the set of criteria defined in the table below. After discussion with the staff of Directors we have been able to fix equivalence and preference thresholds for each qualitative criterion. The ELECTRE III method was run two times using the software ELECTRE III/V Version 3.1b for each set of criteria. Two credibility indices $\sigma\left(\mathrm{a}_{i}, \mathrm{a}_{j}\right)$ and 
$\sigma\left(\mathrm{a}_{j}, \mathrm{a}_{i}\right)$ are calculated each time for each pair of actions $\mathrm{a}_{\mathrm{i}}$ and $\mathrm{a}_{\mathrm{j}}$ of the 22 actions presented in Table 2. This calculation allows us to define an outranking relation between all the actions. It then became possible to draw up both a partial pre-order, that gives the possibility of having a situation of an incomparison between two actions, and a final pre-order presented in Table 3.

Table 3. Ranking of the actions according to two sets of criteria

This table has helped to start a debate between staff of Directors. Indeed, actions 5, 7, 8, 11, 12 and 21 were considered before explaining their preferences as the most important actions to be done to become an OSR. The great majority of these actions are eco-responsible actions which means that they are considered as having a principal impact on the environmental sphere. In fact, the interview done with internal and external actors has shown that the minimum set of actions that have to be done to apply the SD principle are the actions listed below. This is why the achievement of the objective fixed in the action 5 "To control the use of paper" was considered as an emblematic ecoresponsible action for an Expertise Institution and is now considered in the calculation of the profitsharing of the workers of the Institute. Action 8 "To implement a Company Displacement Plan" that is seen as one of the most beneficial actions (rank 2) needs investments. This action has been given overwhelming support by the French Government, who considers action 8 as an interesting strategy to reduce the $\mathrm{CO}_{2}$ emissions during the home-to-work commute.

Action 14 that consists of the development of a solidarity social economy (e.g., provide services to the Institute workers like caretaker's lodge) was at first considered as insignificant, but the ranking has shown that this action does not need a lot of investment, and can have an important impact for working conditions within the Institute.

Action 12 “To control energy consumption of institute buildings” was considered as a leading 20082009 action for the implementation of the eco-responsibility principle. The "Facility Manager" in the Institute is in charge of the implementation of this action. The following section is an illustration of the MCAP chosen to deal with an operational problem.

\subsection{Use of Choquet Integral MCAP for the ranking of operational actions for the execution of the SD action 12 "To control energy consumption of institute buildings"}

The Institute has launched a project for the rehabilitation of the inheritance built within the site of Verneuil (Picardy region in France) where a great part of the buildings are old (60 years or more). In 2008, an audit based on thermograph analysis has revealed that the buildings present an important thermal loss (between 150 and $500 \mathrm{~kW} / \mathrm{m}^{2}$ ). Thus the Institute must establish an energy control 
policy (action 12), regarding French thermal Regulation promulgated in 2005, that has an ambitious energy objective, by reducing more than $30 \%$ of the consumption due to the use of heating.

The actors involved in the implementation of action 12 are working at an operational level. They have heterogeneous quantitative information about different actions that they think are interesting to implement (Category B see section 1.3). They would like to set a priority order on a set of 20 actions (see Table 4) that they have previously been identified.

Table 4. List of 20 actions for the buildings energy control at INERIS

The Buildings $n^{\circ} 3$ and 10 are the most concerned by the implementation of SD action 12 . An expert consulted within the Institute has noticed that due to the age, shape and high level of workers that work in these two buildings, they are at the first rank concerns of restoration.

Due to the fact that all the actions listed below cannot be implemented in the same year considering the fixed budget, it becomes necessary to give a decision aid support to the Division Manager in order to define a plan of works to be done, considering different points of view and criteria.

\subsubsection{Set of attributes and partial assessment of the actions}

Four criteria were identified by analyzing the audit report of 2008 and by considering experts' opinions and the expectations of the final Decision Maker (DM) who is an expert in energy. These criteria (attributes) are both qualitative and quantitative:

Efficiency (Eff). Legitimacy of the work to be done by comparing the investment cost with respect to the effective gain resulting from the action (score from 1 to 4 ).

Energy saving (Energy). Estimation of percentage of the total energy saving (in \%).

Carbon emission avoided (CO2). Estimation of the "equivalent carbon" avoided after the end of the work (in Kg).

Hardness of the work $(H)$. Considering the duration of the work, its scope and its impact on the activity of the employees, the DM attributes a score from 1 to 4 .

The DM would like to obtain a global score on each action. The analyst has then decided to use Choquet integral where the final score is calculated going from partial utility assessment of the action on each criterion to a global utility function.

MACBETH methodology (Bana e Costa and al., 2005) was used to determine the utility functions on each criterion. We first ask the DM to provide two significant levels for each criterion. For the criteria Energy and $\mathrm{CO}$, the DM considers the current situation unacceptable if there is no energy saving and if the avoided carbon emission is equal to $0 \mathrm{~kg}$. A score equal to 1 for the criteria $H$ and 
Eff are considered unacceptable. Then, the DM considers a score equal to 4 for the criteria $H$ and $E f f$ completely satisfactory, equivalent to respectively 30\% economy saving and more than $15 t$ of carbon emission avoided.

The analyst wanted to obtain a utility level between 0 and 20 because this range of information was meaningful for the DM (see figure 7). This way, the information about what is unacceptable and suitable on each criterion was quoted as following: $u_{E f f}(1)=0 \quad u_{E f f}(4)=20$; $u_{\text {Energy }}(0)=0 \quad u_{\text {Energy }}(30)=20 \quad u_{C O 2}(0)=0 \quad u_{C O 2}(15000)=20$ and $u_{H}(1)=0 \quad u_{H}(4)=20$.

Figure 7. Details on the procedure used to define utilities

The MACBETH procedure was used according to M_MACBETH software. The DM was asked to express his preferences on each criterion among all the actions. The DM was also asked to provide a global score (see Table 5) on each action between 0 and 20. Although it was unrealistic to consider that this range of information can always be given, we have assumed that the DM was able to provide it (Table 6). This last information helps the Analyst in defining the expected results viewed by the DM.

Table 5. A partial assessment of the actions

Now that the utility functions are defined, the next steps consist of defining the parameters of the Choquet-like aggregation function and of obtaining a ranking on the actions according to the Choquet integral.The identification method has been implemented within the Kappalab package (Grabisch et al., 2006) for the GNU R (Development Core Team. R., 2005) statistical system where actions are presented as vectors with their partial utility score on each criterion.

\subsubsection{From a partial to a global assessment of the actions}

The global utility function of any action $a$ was given by the following:

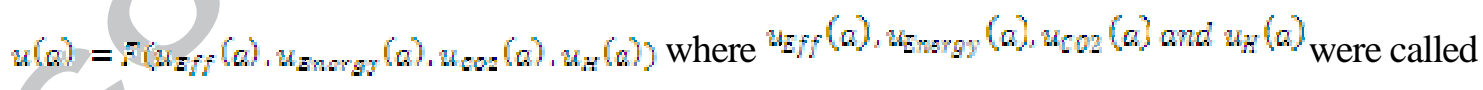
the utility functions and $F$, non-decreasing in its arguments, was called the aggregation function. $a_{E f f}, a_{E n e r g y}, a_{C O 2}$ and $a_{H}$ were the scores (evaluations) given to each action over each criterion.

The overall utilities computed using the Choquet integral were presented in the table below where LS was calculated according to the least squares identification routine based on quadratic programming and HLS was based on the heuristic least squares identification routine.

Table 6. Rankings on the 20 actions 
The Shapley values of the solutions (the Shapley value of $i$ can be thought of as an average value of the marginal contribution $\mu(T \cup\{i\})-\mu(T)$ of criterion $i$ to a subset $T$ not containing it) and the interaction index’s matrices (see figure 8) are given in the following tables:

Figure 8. Shapley values and interaction index's matrices

As one can see, both of the two solutions give the criterion Eff as the most important. In fact, the cost of an action must be justified. The criterion $\mathrm{CO} 2$ is less important for both models. HLS gives the importance of criterion $H$ in second position, slightly weaker than criterion Eff. On the contrary, the LS model gives quasi identical importance to $H$ and Energy. This difference can be explained by the small amount of data.

Both models give rise to the three most important criteria. $\mathrm{CO} 2$ does not seem to affect the global evaluation of an action. Concerning the interactions, we can see that Eff and Energy are complementary, whereas Eff and $H$ are redundant. The rest of the pairs are quasi-independent. According to these observations, we have finally explicated the global score $e$ of an action $a$ in the case of a 2-additive capacity where the variables $a_{E f f}, a_{\text {Energy }}, a_{C O 2}$ and $a_{H}$ are the scores on each

The 20 actions were ranked from the least important to the most important (see Table 7).

$$
e=0.03 a_{E f f}+0.04 a_{E n e r g y}+0.01 a_{C O 2}+0.01 a_{H}+0.23\left(a_{E f f} \wedge a_{E n e r g y}\right)+0.19\left(a_{E f f} \vee a_{C O 2}\right)+
$$

criterion: $\quad 0.29\left(a_{E f f} \vee a_{H}\right)+0.08\left(a_{\text {Energy }} \wedge a_{C O 2}\right)+0.05\left(a_{\text {Energy }} \wedge a_{H}\right)+\left(a_{C O 2} \wedge a_{H}\right)$.

Table 7. Ranking of the 20 actions from the least important to the most important

The expected planning of works (ranking on actions) (see Table 7) was almost respected and accepted, except for actions 4, 9 and 3. In fact, the decision aid process applied using Choquet integral has offered the opportunity to the DM to reconsider some of his preferences on actions.

\section{Discussion and conclusion}

The Sustainable Development (SD) principle is difficult to implement within an Organization. SD principle seeks for more participation and more accountability in framing decision and choosing short and long terms actions to reach sustainability. There is rarely an optimal solution in SD but most frequently a need to build compromises between conflicting aspects such as economic, social and environmental ones and different expectations of stakeholders. Moreover, information is rarely available and precise. In this paper we have used a Multi-Criteria Decision Aid (MCDA) methodology to cope with these difficulties.

MCDA methodology offers the opportunity to avoid monetization of the different dimensions of the SD. These dimensions are not substitutable for one another and all have a role to play. MCDA is a 
branch of decision theory where actions or alternatives are chosen considering several points of view or criteria, assuming that the decision maker (DM) has all the information at his disposal concerning the alternatives, i.e., they are fully described by a vector of attributes which is supposed to be known without uncertainty. Two main features of this kind of problem make it difficult to solve. The first one is that attributes describing alternatives are heterogeneous, i.e., they represent different physical (or economical, subjective ... .) entities like price, size, color, weight, etc. and may be numerical or not. Hence a first difficulty is to make them commensurable in some sense. The second feature is that points of view or criteria are more or less important to make a decision, and most often they are conflicting or interacting in some way, so that it is not obvious how to combine them for reaching a final overall opinion.

There are several possible aggregation procedures in MCDA methodology. We have proposed a method to choose an adequate aggregation procedure for SD problems. Outranking approach (i.e., ELECTRE) easily solves the commensurateness problem by making pair wise comparisons. Monocriterion synthesis approaches (i.e., MAUT approaches) rely on the construction of utility functions, which can be fairly difficult because of incommensurability problems, but then easily reach a final decision by combining utilities or scores of all criteria.

In this paper we have implemented two aggregation procedures to rank SD actions within a public Organization: ELECTRE III at a strategical level of decision and MAUT method based on the Choquet integral at an operational level of decision within an expertise Institute. Both methods present advantages and difficulties in a real life situation. The implementation of the ELECTRE III method for the ranking of 22 SD actions offer the opportunity to discuss incomparability situations (R) where the actors involved can discuss their different visions and opinions about the implementation of the SD actions. However, the interest of the relation R is lost when dealing with more than 100 actions. That is due to the difficulty to read the final graph with all the comparison situations (I, P, Q, R). The Analyst is then obliged to use the final pre-order to communicate the results. But let us note that this method is easy to understand and communicate, perhaps due to the fact that the actors involved were familiar with this method that was used in daily situations for risk management and risk analysis problems (i.e., pesticide ranking, industrial accident scenario ranking, etc.). Nevertheless, it is difficult to explain to the DM that the final pre-order can change if new SD actions are introduced. Even if actors understand that this result is due to a pair wise comparison, they still consider that it is due to the non robustness of the method.

The implementation of the MAUT method based on Choquet integral was very helpful at an operational level. First, the engineer culture within the Institute is familiar with numbers and they 
appreciate the results of this method that offer the possibility of having a final score on actions that respect the incommensurability between the criteria. Second, this method offers the possibility of building a real interaction between the Analyst and the DM and testing the coherence on the action ranking. However, the main inconvenience is to request the DM to give a preliminary desired global score on the actions. This can be possible if the DM has a limited set of actions and if he knows the actions that he has to rank well.

One year after the implementation of the SD plan, the Ministry of Finance and Industry and the Ministry of Environment were both attracted by the ability of the MCDA methods to reach the goal of more transparency, more accountability and more participation in the way public funding are spent and the goal of sustainability is achieved. The Institute is now engaged in a sharing methodological process within the 60 public Organizations that are members of the SD French club.

In 2011, The Institute has started framing its second SD Plan for the period 2012-2015. The experience feedback learned from the implementation of the $1^{\text {st }} \mathrm{SD}$ plan was that even if the participative process (including the 600 workers of the Institute and the other large set of stakeholders) was long, hard and expensive one, it has reach the objectives of being effective, legitimated by and transparent to all stakeholders. All the actions identified in the SD action plan were implemented and followed each year by the staff of Directors. Let us notice that even if one of the challenges of the SD plan was to open the scope of sustainability to social and economical dimensions, the first set of actions that was implemented was the one with the more environmental expected benefit (see table 1). We do think that this is due to the fact that these actions were the more strongly regulated by the environmental legislation.

\section{References}

1. BEHZADIAN M., KAZEMZADEH R.B., ALBADVI A., AGHDASI M. "PROMETHEE: A comprehensive literature review on methodologies and applications”. European journal of Operational research, Volume 200, Issue 1, Pages 198-215, 2010,

2. BANA E COSTA C.A., DE CORTE J.M., and VANSNICK J.C. "On the Mathematical Foundation of MACBETH”. In J. Figueira, S. Greco, and M. Ehrgott, editors, Multiple Criteria Decision Analysis: State of the Art Surveys, pages 409-443. Springer Verlag, Boston, Dordrecht, London, 2005.

3. CHEVALLIER J.J. "DPM, Démarche Participative Multicritère pour la gestion environnementale”. Groupe de recherche interdisciplinaire pour le développement durable (GRIDD), Université de Laval, Québec, 20 p., 1999. 
4. DE MONTIS, A., DE TORO, P., DROSTE-FRANKE, B., OMANN, I. AND STAGL, S. Sustainable Development and Evaluation: Some Criteria for Quality Assessment of MCDA Methods. Revista Multidisciplinar de Gestion Ambiental 51, 18-27, 2003.

5. DE MONTIS, A., DE TORO, P., DROSTE-FRANKE, B., OMANN, I. AND STAGL, S. Criteria for Quality Assessment of MCDA-methods. In M. Getzner, C. Spash and S. Stagl Editions, Developing Alternatives for Valuing Nature, Routledge, 61-87, 2004.

6. DEVELOPMENT CORE TEAM. R.. “A language and environment for statistical computing”. R Foundation for Statistical Computing, Vienna, Austria. ISBN 3- 900051-00-3, 2005.

7. FAUCHEUX S., FROGER G., MUNDA G., "Multicriteria Decision Aid and the Sustainability Tree», in FAUCHEUX S. and O’CONNOR M., (ed.), Valuation for Sustainable Development: methods and policy indicators, Edward Elgar, Advances in Ecological Economics Series, pp. 187-214, 1998.

8. GIRARD L.F., DE TORO P. "Integrated spatial assessment: a multicriteria approach to sustainable development of cultural and environmental heritage in San Marco dei Cavoti, Italy”. CEJOR, 15:281-299, 2007.

9. GRABISCH M., KOJADINOVIC I., MEYER P. “kappalab: Non additive measure and integral manipulation functions”, R package version 0.3, 2006.

10. GUITOUNI A, MARTEL J-M. Tentative guidelines to help choosing an appropriate MCDA method. European Journal of Operational Research, Volume 109, Issue 2, 501-521, 1998.

11. HOKKANEN J., LAHDELMA R., MIETTINEN K., SALMINEN P. "Determining the Implementation Order of a General Plan by Using a Multicriteria Method”. J. Multi-Crit. Decis. Anal. 7: 273-284, 1998.

12. HOKKANEN J., SALMINEN P. "ELECTRE III and IV Decision Aids in an Environmental Problem”. Journal of multi-criteria decision analysis, VOL 6, 215 - 226, 1997.

13. HOKKANEN J., SALMINEN P. "Locating a Waste Treatment Facility by Multicriteria Analysis». J. Multi-Crit. Decis. Anal. 6: 175 - 184, 1997.

14. JANSSEN R. "Multiobjective decision support for environmental problems". Kluwer, Dordrecht, 1992.

15. KANGAS J., KANGAS A., LESKINEN P., PYKÄLÄINEN J. (2001). "MCDM Methods in Strategic Planning of Forestry on State-Owned Lands in Finland: Applications and Experiences”. J. Multi-Crit. Decis. Anal. 10: 257-271, 1992.

16. KOWALSKI K., STAGL S., MADLENER R., OMANN I. "Sustainable energy futures: Methodological challenges in combining scenarios and participatory multi-criteria analysis”. European Journal of Operational Research 197, 1063 - 1074, 2009. 
17. LABREUCHE Ch. and GRABISCH M. "Generalized Choquet-like aggregation functions for handling bipolar scales”. European Journal of Operational Research, Vol 172 , 2006, 931-955.

18. MAYSTRE L.Y., BOLLINGER D. “Aide à la négociation multicritère”. Presse Polytechniques et Universitaires Romandes, Collection gérer l'environnement, Lausanne, 1999.

19. MAYSTRE L.Y., PICTET J., SIMOS J. "Méthodes multicritères ELECTRE : Description, conseils pratiques et cas d'application à la gestion environnementale”, Presses Polytechniques et Universitaires Romandes, Collection gérer l'environnement, Lausanne, 1994.

20. MERAD M., Aide à la décision et expertise en gestion des risques. Editions Lavoisier. 256 pages. ISBN : 978-2-7430-1265-6, Paris, 2010.

21. MERAD M., VERDEL T., ROY B., KOUNIALI S. Use of multi-criteria decision-aids for risk zoning and management of large area subjected to mining-induced hazards. Tunnelling and Underground Space Technology, Volume 19, Issue 2, March 2004, Pages 125-138.

22. MERAD M., Post mining management in the Lorraine region: method of grading of mining subsidence risk under building and infrastructure. 12th SRA Europe Annual Meeting, 21-24 juillet 2002, Berlin, Allemagne, 2002.

23. MUNDA G. “Multicriteria Evaluation in a Fuzzy Environment”. Physica- Verlag, Heidelberg, Allemagne, 1995.

24. MUROFUSHI T., SONEDA S. "Techniques for reading fuzzy measures (III): interaction index (in Japanese)”. In: 9th fuzzy system symposium.. Sapporo, pp 693-696, 1993

25. OMANN I., Multi-criteria decision aid as an approach for sustainable development analysis and implementation, PHD Thesis, 2004.

26. PARUCCINI M., “Applying Multiple Criteria Aid for Decision to Environmental Management”. Kluwer Academic Publishers, Dordrecht-Boston, London, 1994.

27. RAMANATHANI R., GANESH L. S. "Energy Resource Allocation Incorporating Qualitative and Quantitative Criteria: An Integrated Model Using Goal Programming and AHP”. SocioEcon. Plann. Sci. Vol. 29, No. 3, pp. 197-218, 1995.

28. REZAEI-MOGHADDAM K., KARAMI E. “A multiple criteria evaluation of sustainable agricultural development models using AHP”. Environ Dev Sustain, 10:407-426, 2008.

29. ROY B., BOUYSSOU D. Aide multicritère à la décision, Paris, Economica, pp. 415-434, 1992.

30. FIGUEIRA J., ROY B. Determining the weights of criteria in the ELECTRE type methods with a revised Simos' procedure. European Journal of Operational Research, Volume 139, Issue 2, 1 June 2002, Pages 317-326 
31. VINCKE, Ph. Analysis of multicriteria decision aid in Europe. European Journal of Operational Research, Volume 25, Issue 2, May 1986, Pages 160-168. 


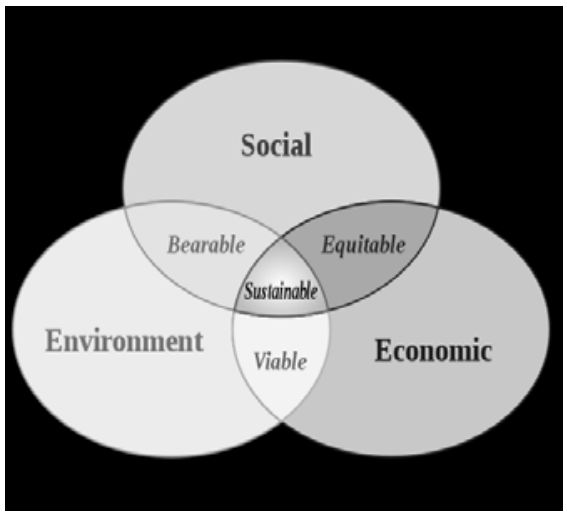

Figure 1. Sustainable Development principle
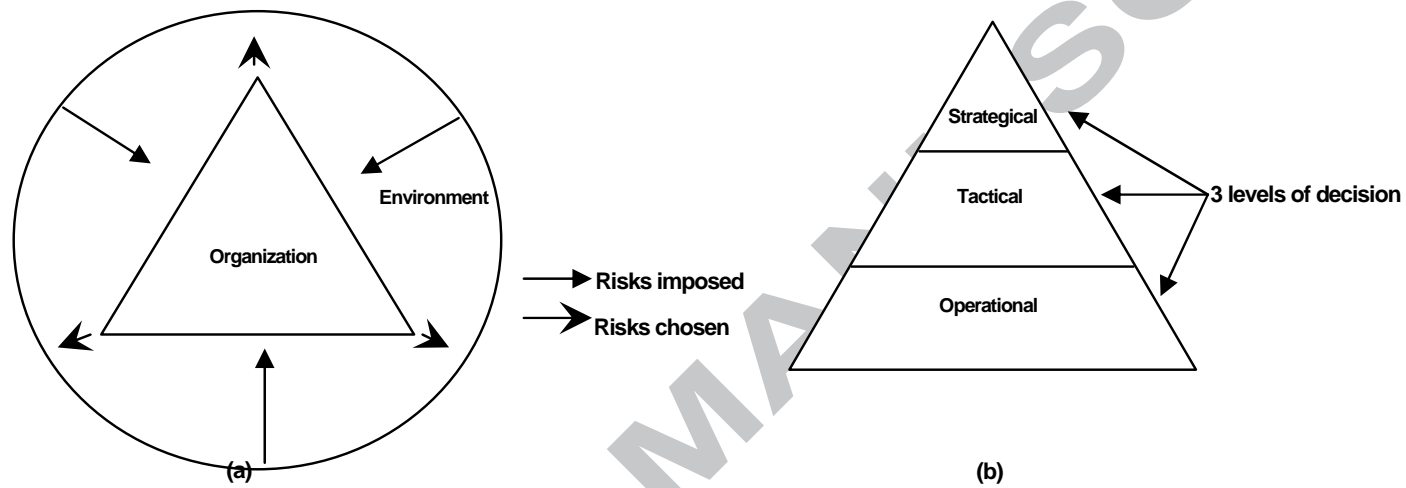

(b)

Figure 2. The Organization and its environment (a) and 3 levels of decision in the Organization (b)

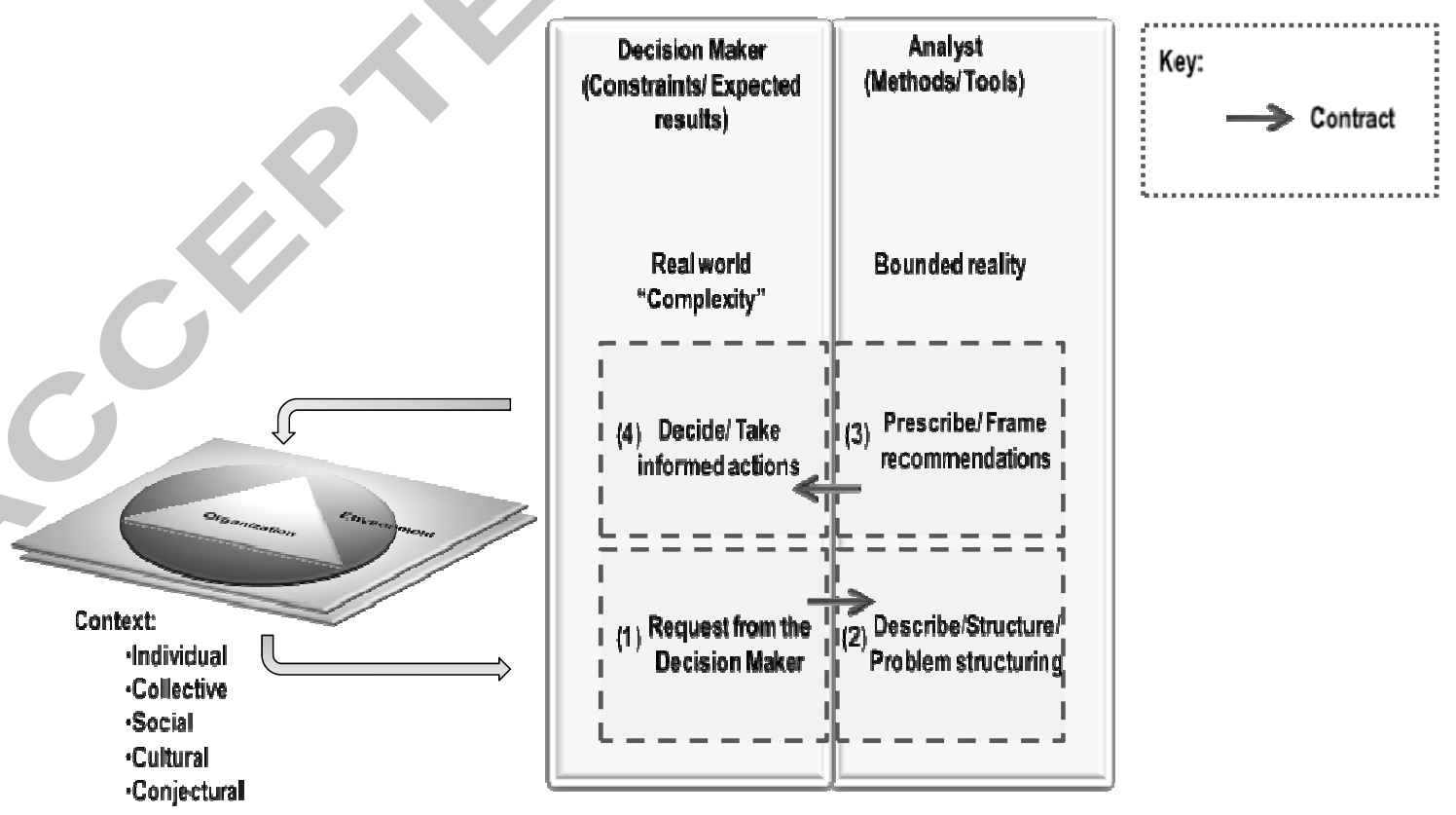

Figure 3. Multi-criteria decision aid methodology: the link between the Analyst and the Decision Maker 


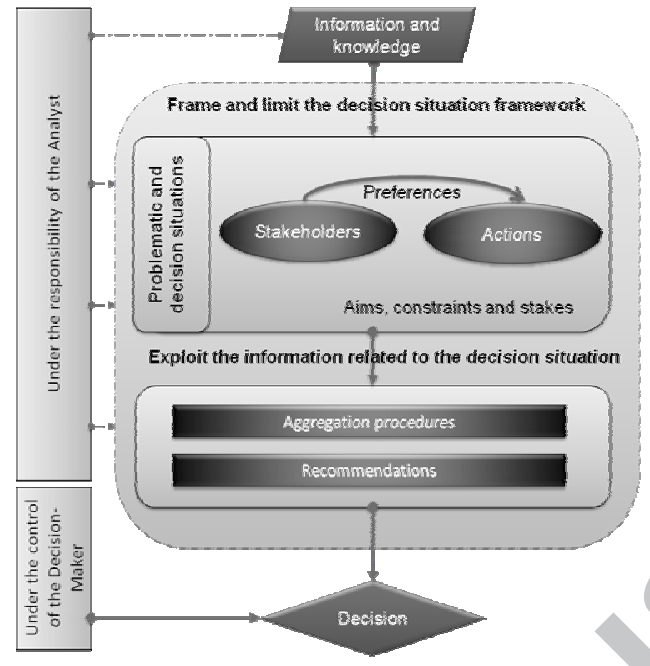

Figure 4. Multi-criteria decision aid method applied to the implementation of the SD principle

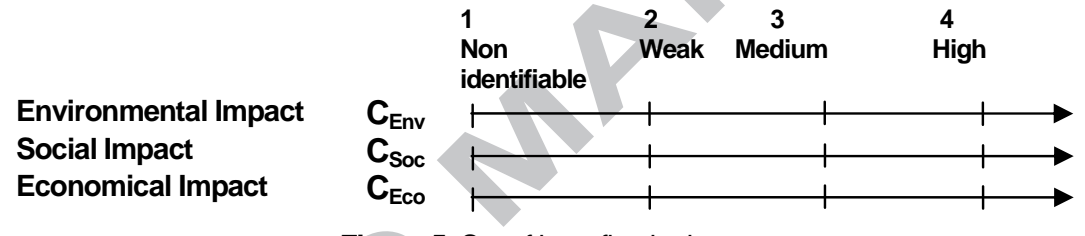

Figure 5. Set of benefit criteria

Internal expenses

External expenses

Investments

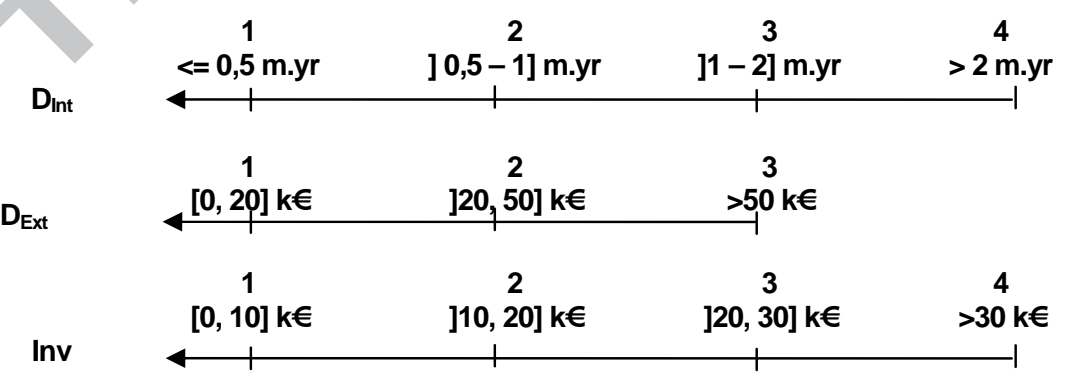

Figure 6. Set of cost criteria

* m.yr: Man/year

* $1 \mathrm{k} €=1000$ euro. 


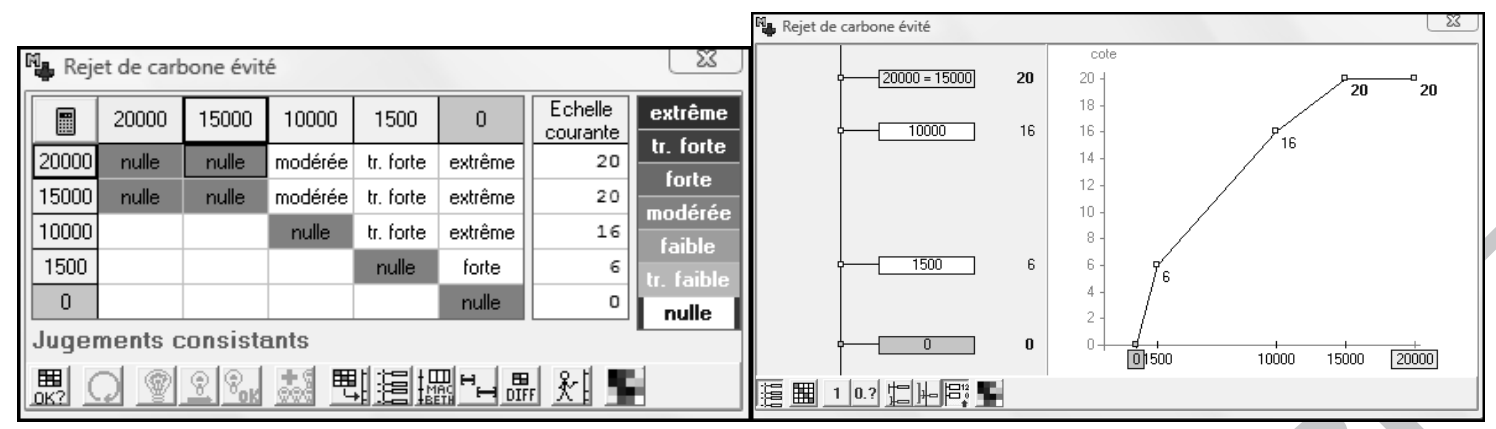

Figure 7. Details on the procedure used to define utilities

* "Jugements consistants": consistant judgments. **"Rejet de carbone évité": carbone rejection avoidance.

\begin{tabular}{|c|c|c|c|c|}
\hline & Eff & Energy & CO2 & $\boldsymbol{H}$ \\
\hline LS & 1.50 & 0.89 & 0.71 & 0.87 \\
\hline HLS & 1.29 & 0.80 & 0.69 & 1.21 \\
\hline
\end{tabular}

\begin{tabular}{|l|c|c|c|c|}
\hline LS & Eff & Energy & CO2 & $\boldsymbol{P}$ \\
\hline Eff & NA & 0.23 & -0.19 & -0.29 \\
\hline Energy & & NA & 0.08 & 0.05 \\
\hline CO2 & & & NA & -0.08 \\
\hline $\boldsymbol{P}$ & & & & NA \\
\hline
\end{tabular}

\begin{tabular}{|l|c|c|c|c|}
\hline HLMS & Eff & Energy & CO2 & $\boldsymbol{P}$ \\
\hline Eff & NA & 0.10 & -0.18 & -0.16 \\
\hline Energy & & NA & 0.10 & 0.08 \\
\hline CO2 & & & NA & -0.08 \\
\hline $\boldsymbol{P}$ & & & & NA \\
\hline
\end{tabular}

Figure 8. Shapley values and interaction index's matrices

Table 1. List of 22 SD actions for INERIS

\begin{tabular}{|c|c|c|c|c|}
\hline \multirow{2}{*}{ Id. } & \multirow{2}{*}{ Description } & \multicolumn{3}{|c|}{ SD domains } \\
\hline & & Environmental & Social & Economic \\
\hline 1 & $\begin{array}{l}\text { Office automation: for } 2010,60 \% \text { of the newly bought materials } \\
\text { must have performance equivalent to the TCO Swedish } \\
\text { reference, and comprise a minimum percentage of recycled } \\
\text { materials. }\end{array}$ & $\checkmark$ & & \\
\hline 2 & $\begin{array}{l}\text { To increase the percentage of products coming from biological } \\
\text { agriculture in the collective restoration services. }\end{array}$ & $\checkmark$ & $\checkmark$ & \\
\hline 3 & To check the sources of origin of wooden products. & $\checkmark$ & $\checkmark$ & \\
\hline 4 & To use eco-labeled products for building cleaning. & $\checkmark$ & & \\
\hline 5 & To control the use of paper. & $\checkmark$ & & \\
\hline 6 & $\begin{array}{l}\text { To inform and raise awareness among the staff about eco- } \\
\text { driving during work displacements. }\end{array}$ & $\checkmark$ & & \\
\hline 7 & $\begin{array}{l}\text { To only have vehicles (private cars) with less than } 130 \mathrm{~g} \text { of } \\
\text { CO } 2 / \mathrm{km} \text {. }\end{array}$ & $\checkmark$ & & \\
\hline 8 & To implement a Company Displacement Plan. & $\checkmark$ & & \\
\hline 9 & To control waste management. & $\checkmark$ & & \\
\hline 10 & $\begin{array}{l}\text { To have a reasonable management of Parks and of the } \\
\text { arborical patrimony within the Institute. }\end{array}$ & $\checkmark$ & & \\
\hline 11 & To remove ink-jet printers for 2010 & $\checkmark$ & & \\
\hline 12 & To control energy consumption of institute buildings. & $\checkmark$ & & \\
\hline 13 & To implement durable policy of sourcing. & & & $\checkmark$ \\
\hline 14 & To contribute to the development of a solidarity social economy. & & $\checkmark$ & $\checkmark$ \\
\hline 15 & $\begin{array}{l}\text { To consolidate the partnerships with the different actors of the } \\
\text { SD. }\end{array}$ & & $\checkmark$ & \\
\hline 16 & $\begin{array}{l}\text { To develop new managerial practices with respect to SD } \\
\text { principles. }\end{array}$ & & $\checkmark$ & \\
\hline 17 & $\begin{array}{l}\text { To develop better career management and to improve the well } \\
\text { being in the Institute. }\end{array}$ & & $\checkmark$ & \\
\hline 18 & $\begin{array}{l}\text { To invest the Institute in the social responsibility by taking care } \\
\text { of our responsibility in handicap integration. }\end{array}$ & & $\checkmark$ & \\
\hline 19 & $\begin{array}{l}\text { To implement a strategic watch in the field of SD to support } \\
\text { project leaders and managers within the Institute. }\end{array}$ & & $\checkmark$ & $\checkmark$ \\
\hline 20 & $\begin{array}{l}\text { To develop the exchanges of knowledge and know-how with } \\
\text { our foreign partners and to capitalize the good practices. }\end{array}$ & & $\checkmark$ & \\
\hline
\end{tabular}


\begin{tabular}{|c|c|}
\hline 21 & To reinforce the links between INERIS and NGOs.
\end{tabular}

\begin{tabular}{|l|l}
\hline 22 & To develop a SD culture within the Institute.
\end{tabular}

Table 2. Impacts SD Dashboard

\begin{tabular}{|c|c|c|c|c|c|c|}
\hline & \multicolumn{3}{|c|}{ Expected benefits } & \multicolumn{3}{|c|}{ Expected costs } \\
\hline $\begin{array}{c}\text { Id. } \\
\text { SD Actions }\end{array}$ & $C_{E n v}$ & $\mathrm{C}_{\mathrm{Soc}}$ & $\mathrm{C}_{\mathrm{Eco}}$ & $D_{\text {lnt }}$ & $D_{\text {Ext }}$ & Inv \\
\hline 1 & 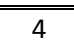 & 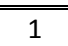 & 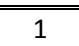 & 0 & 0 & 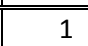 \\
\hline 2 & 4 & 3 & 1 & 0 & 3 & 1 \\
\hline 3 & 3 & 3 & 1 & 0 & 2 & 2 \\
\hline 4 & 3 & 1 & 1 & 0 & 1 & 0 \\
\hline 5 & 4 & 1 & 1 & 1 & 2 & 0 \\
\hline 6 & 1 & 2 & 1 & 1 & 1 & 0 \\
\hline 7 & 3 & 1 & 1 & 0 & 0 & 2 \\
\hline 8 & 2 & 4 & 3 & 1 & 0 & 2 \\
\hline 9 & 3 & 2 & 1 & 1 & 2 & 4 \\
\hline 10 & 4 & 1 & 2 & 1 & 0 & 0 \\
\hline 11 & 3 & 1 & 1 & 1 & 1 & 0 \\
\hline 12 & 4 & 2 & 3 & 0 & 0 & 4 \\
\hline 13 & 1 & 3 & 2 & 1 & 0 & 1 \\
\hline 14 & 1 & 4 & 3 & 0 & 1 & 0 \\
\hline 15 & 1 & 3 & 3 & 2 & 0 & 0 \\
\hline 16 & 2 & 4 & 2 & 1 & 1 & 0 \\
\hline 17 & 1 & 4 & 3 & 1 & 1 & 0 \\
\hline 18 & 1 & 4 & 1 & 1 & 0 & 1 \\
\hline 19 & 1 & 3 & 3 & 1 & 0 & 1 \\
\hline 20 & 1 & 3 & 1 & 1 & 0 & 0 \\
\hline 21 & 1 & 3 & 2 & 2 & 0 & 0 \\
\hline 22 & 3 & 4 & 4 & 1 & 1 & 0 \\
\hline \multicolumn{7}{|l|}{ Thresholds } \\
\hline$q$ & 1 & 1 & 1 & 1 & 1 & 1 \\
\hline $\mathbf{p}$ & 1 & 1 & 1 & 1 & 1 & 1 \\
\hline Weights & 100 & 100 & 100 & 62 & 38 & 62 \\
\hline
\end{tabular}


Table 3. Ranking of the actions according to two sets of criteria

\begin{tabular}{|c|c|c|}
\hline $\begin{array}{c}\text { Final pre- order } \\
\text { (Rank) }\end{array}$ & $\begin{array}{c}\text { Priority order on } \\
\text { actions according to } \\
\text { benefit criteria }\end{array}$ & $\begin{array}{c}\text { Priority order on actions } \\
\text { according to cost criteria }\end{array}$ \\
\hline $\mathbf{1}$ & 22 & 14 and 4 \\
\hline $\mathbf{2}$ & $\mathbf{1 2}$ and 8 & 10,20 and 1 \\
\hline $\mathbf{3}$ & 14,2 and 17 & $11,6,16,17$ and 22 \\
\hline $\mathbf{4}$ & 3 and 16 & 13,18 and 19 \\
\hline $\mathbf{5}$ & 9,15 and 19 & 15,21 and 7 \\
\hline $\mathbf{6}$ & 10 & 5 and 8 \\
\hline $\mathbf{7}$ & 1 and 5 & $\mathbf{1 2}$ and 2 \\
\hline $\mathbf{8}$ & $13,11,4,7$ and 21 & 3 \\
\hline $\mathbf{9}$ & 18 & 9 \\
\hline $\mathbf{1 0}$ & 20 & \\
\hline $\mathbf{1 1}$ & 6 & \\
\hline
\end{tabular}

Table 4. List of 20 actions for building energy control at INERIS

\begin{tabular}{|c|c|c|c|c|c|c|c|}
\hline \multirow[b]{2}{*}{ Id. } & \multirow[b]{2}{*}{ Description } & \multicolumn{6}{|c|}{ Buildings } \\
\hline & & $\begin{array}{l}\text { Building } \\
n^{\circ} 3\end{array}$ & $\begin{array}{l}\text { Building } \\
n^{\circ} 4\end{array}$ & $\begin{array}{l}\text { Building } \\
n^{\circ} 5\end{array}$ & $\begin{array}{l}\text { Building } \\
\mathrm{n}^{\circ} 7\end{array}$ & $\begin{array}{l}\text { Building } \\
\mathrm{n}^{\circ} 10\end{array}$ & $\begin{array}{l}\text { Building } \\
\mathrm{n}^{\circ} 79\end{array}$ \\
\hline Ac.12-1 & Insulation of the roof & & 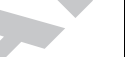 & & & $\checkmark$ & \\
\hline Ac.12-2 & Insulation of the roof & $\checkmark$ & & & & & \\
\hline Ac.12-3 & Insulation of the external walls & 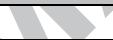 & & & & $\checkmark$ & \\
\hline Ac.12-4 & Insulation of the external walls & $\checkmark$ & & & & & \\
\hline Ac. $12-5$ & $\begin{array}{l}\text { Replacement of the exterior wood } \\
\text { finishings }\end{array}$ & $\checkmark$ & & & & & \\
\hline Ac.12-6 & $\begin{array}{l}\text { Replacement of the exterior wood } \\
\text { finishings }\end{array}$ & & & & & $\checkmark$ & \\
\hline Ac.12-7 & Installation of solar panels $\mathrm{DHW}^{2}$ & & & & $\checkmark$ & & \\
\hline Ac.12-8 & Installation of solar panels DHW & & & & & & \\
\hline Ac.12-9 & Installation of an electric optimizer & & & $\mathrm{v}$ & & & \\
\hline Ac. $12-10$ & Replacement of the bodies of adjustment & $\checkmark$ & & & & & \\
\hline Ac.12-11 & Replacement of the bodies of adjustment & & & & & $\checkmark$ & \\
\hline Ac.12-12 & Creation of a boiler room & & & & & & \\
\hline Ac.12-13 & Creation of a sub-station & & & & & $\checkmark$ & \\
\hline Ac.12-14 & Creation of a sub-station & & $\checkmark$ & & & & $\checkmark$ \\
\hline Ac.12-15 & Creation of a sub-station & & & $\checkmark$ & & & \\
\hline Ac.12-16 & Creation of a sub-station & & & & & & $\checkmark$ \\
\hline Ac.12-17 & Installation of a recuperator of DHW & & & & $\checkmark$ & & \\
\hline Ac.12-18 & Installation of a recuperator of DHW & & & & & $\checkmark$ & \\
\hline Ac.12-19 & Installation of a CMV2F ${ }^{3}$ & & & & & $\checkmark$ & \\
\hline Ac. $12-20$ & Installation of a CMV2F & $\checkmark$ & & & & & \\
\hline
\end{tabular}

\footnotetext{
${ }^{2}$ Domestic Hot Water.

${ }^{3}$ Controlled Mechanical Ventilation with Double Flow.
} 
Table 5. A partial assessment of the actions

\begin{tabular}{|c|c|c|c|c|c|}
\hline & $u_{E f f}$ & $u_{\text {Energy }}$ & $u_{C O 2}$ & $u_{H}$ & $\begin{array}{c}\text { Global score } \\
\text { given by the DM }\end{array}$ \\
\hline Ac.12-1 & 4.5 & 0.26 & 0.95 & 0 & 2 \\
\hline Ac.12-2 & 4.5 & 0.92 & 1.73 & 0 & 2.25 \\
\hline Ac.12-3 & 9 & 5.12 & 9.59 & 20 & 11.5 \\
\hline Ac.12-4 & 9 & 6.57 & 7.84 & 15 & 11 \\
\hline Ac.12-5 & 18 & 6.94 & 8.05 & 7.50 & 12.25 \\
\hline Ac.12-6 & 18 & 4.70 & 9.15 & 15 & 12 \\
\hline Ac.12-7 & 18 & 20 & 14.02 & 17.5 & 16 \\
\hline Ac.12-8 & 18 & 20 & 5.13 & 20 & 17.75 \\
\hline Ac.12-9 & 9 & 3.93 & 20 & 15 & 11 \\
\hline Ac.12-10 & 9 & 8.99 & 9.17 & 11.25 & 10.25 \\
\hline Ac.12-11 & 9 & 9 & 13.63 & 11.25 & 10.75 \\
\hline Ac.12-12 & 4.5 & 9 & 20 & 7.50 & 11 \\
\hline Ac.12-13 & 16 & 9.01 & 13.63 & 15 & 13.75 \\
\hline Ac.12-14 & 16 & 9 & 13.08 & 15 & 13.75 \\
\hline Ac.12-15 & 16 & 9 & 8.81 & 15 & 12.75 \\
\hline Ac.12-16 & 16 & 8.99 & 9.15 & 15 & 13 \\
\hline Ac.12-17 & 18 & 20 & 8.94 & 20 & 19 \\
\hline Ac.12-18 & 18 & 20 & 2.40 & 20 & 17.5 \\
\hline Ac.12-19 & 18 & 12.80 & 4 & 11.25 & 14.75 \\
\hline Ac.12-20 & 18 & 12 & 4 & 7.50 & 14.5 \\
\hline & & & & & \\
\hline
\end{tabular}

Table 6. Rankings on the 20 actions

\begin{tabular}{|c|c|c|c|}
\hline & $\begin{array}{c}\text { Desired } \\
\text { global } \\
\text { assessment }\end{array}$ & LS & HLS \\
\hline Ac.12-1 & 2 & 2.43 & 2.15 \\
\hline Ac.12-2 & 2.25 & 2.73 & 2.31 \\
\hline Ac.12-3 & 11.5 & 11.73 & 12.66 \\
\hline Ac.12-4 & 11 & 10.30 & 10.74 \\
\hline Ac.12-5 & 12.25 & 12.58 & 12.18 \\
\hline Ac.12-6 & 12 & 12.27 & 12.56 \\
\hline Ac.12-7 & 16 & 17.69 & 17.42 \\
\hline Ac.12-8 & 17.75 & 17.93 & 17.55 \\
\hline Ac.12-9 & 11 & 11.75 & 11.57 \\
\hline Ac.12-10 & 10.25 & 9.89 & 9.98 \\
\hline Ac.12-11 & 10.75 & 10.95 & 10.66 \\
\hline Ac.12-12 & 11 & 10.40 & 10.73 \\
\hline Ac.12-13 & 13.75 & 13.04 & 13.53 \\
\hline Ac.12-14 & 13.75 & 13.04 & 13.45 \\
\hline Ac.12-15 & 12.75 & 13.02 & 12.83 \\
\hline Ac.12-16 & 13 & 13.03 & 12.87 \\
\hline Ac.12-17 & 19 & 18.24 & 18.02 \\
\hline Ac.12-18 & 17.5 & 17.72 & 17.20 \\
\hline Ac.12-19 & 14.75 & 14.49 & 13.86 \\
\hline Ac.12-20 & 14.5 & 13.73 & 13.08 \\
\hline
\end{tabular}


Table 7. Ranking of the 20 actions from the least important to the most important

\begin{tabular}{|c|c|c|c|c|c|c|c|}
\hline & \multirow{2}{*}{ Id. } & \multicolumn{6}{|c|}{ Buildings } \\
\hline & & Building $n^{\circ} 3$ & Building $n^{\circ} 4$ & Building $n^{\circ} 5$ & Building $\mathrm{n}^{\circ} 7$ & Building $n^{\circ} 10$ & Building $n^{\circ} 79$ \\
\hline \multirow{19}{*}{$\begin{array}{c}\text { Least } \\
\text { important }\end{array}$} & Ac.12-1 & & & & & $\checkmark$ & \\
\hline & Ac.12-2 & $\checkmark$ & & & & & \\
\hline & Ac. $12-10$ & $\checkmark$ & & & & & \\
\hline & Ac.12-11 & & & & & $\checkmark$ & 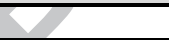 \\
\hline & Ac.12-12 & \multicolumn{6}{|c|}{$\checkmark$} \\
\hline & Ac. 12-4 & $\checkmark$ & & & & & \\
\hline & Ac. $12-9$ & \multicolumn{6}{|c|}{$\checkmark$} \\
\hline & Ac. 12-3 & & & & & $\checkmark$ & \\
\hline & Ac. $12-6$ & & & & & $\checkmark$ & \\
\hline & Ac. 12-5 & $\checkmark$ & & & & $\bar{r}$ & \\
\hline & Ac. $12-15$ & & & $\checkmark$ & & & \\
\hline & Ac. $12-16$ & & & & & & $\checkmark$ \\
\hline & Ac. 12-13 & & & & 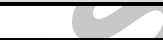 & $\checkmark$ & \\
\hline & Ac.12-14 & & $\checkmark$ & & & & $\checkmark$ \\
\hline & Ac. $12-20$ & $\checkmark$ & & & 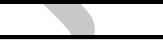 & & \\
\hline & Ac. $12-19$ & & & & & $\checkmark$ & \\
\hline & Ac. 12-7 & & & 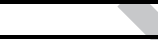 & 5 & & \\
\hline & Ac. 12-18 & & & $\bar{C}$ & 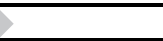 & $\checkmark$ & \\
\hline & Ac. $12-8$ & \multicolumn{6}{|c|}{$\checkmark$} \\
\hline $\begin{array}{c}\text { Most } \\
\text { important }\end{array}$ & Ac. $12-17$ & & & & $\checkmark$ & & \\
\hline
\end{tabular}




\title{
Using a multi-criteria decision aid methodology to implement sustainable development principles within an Organization
}

\author{
Myriam Merad* , Nicolas Dechy* ${ }^{4}$, Lisa Serir**, Michel Grabisch***, Frédéric Marcel* \\ * INERIS-BP 2 - F60550 Verneuil-en-Halatte (France) (e-mail : myriam.merad@ineris.fr, tel: +33 (0) 3445569 25) \\ ** Département Automatique et Systèmes Micro-Mécatroniques, TEMIS, 24 r Alain Savary, F-25000 Besançon (France) \\ *** Centre d'Économie de la Sorbonne, 106-112, Bd de l'Hôpital, 75013 Paris (France)
}

\section{Highlights}

There is rarely an optimal solution in Sustainable Development (SD).

MCDA methodology offers the opportunity to avoid monetization of the different dimensions of the SD.

We have proposed a method to choose an adequate aggregation procedure for SD problems.

We have implemented two aggregation procedures to rank SD actions within a public Organization: ELECTRE III and MAUT.

${ }^{4}$ N. Dechy was at INERIS during the study and is now working at IRSN. 